\title{
MEMÓRIAS DA PLANTAÇÃO: EPISÓDIOS DE RACISMO COTIDIANO
}

\section{PLANTATION MEMORIES: EPISODES OF EVERYDAY RACISM}

(iD) Patricia Lorena Raposo ${ }^{1}$

(iD) Maciana de Freitas e Souza ${ }^{2}$

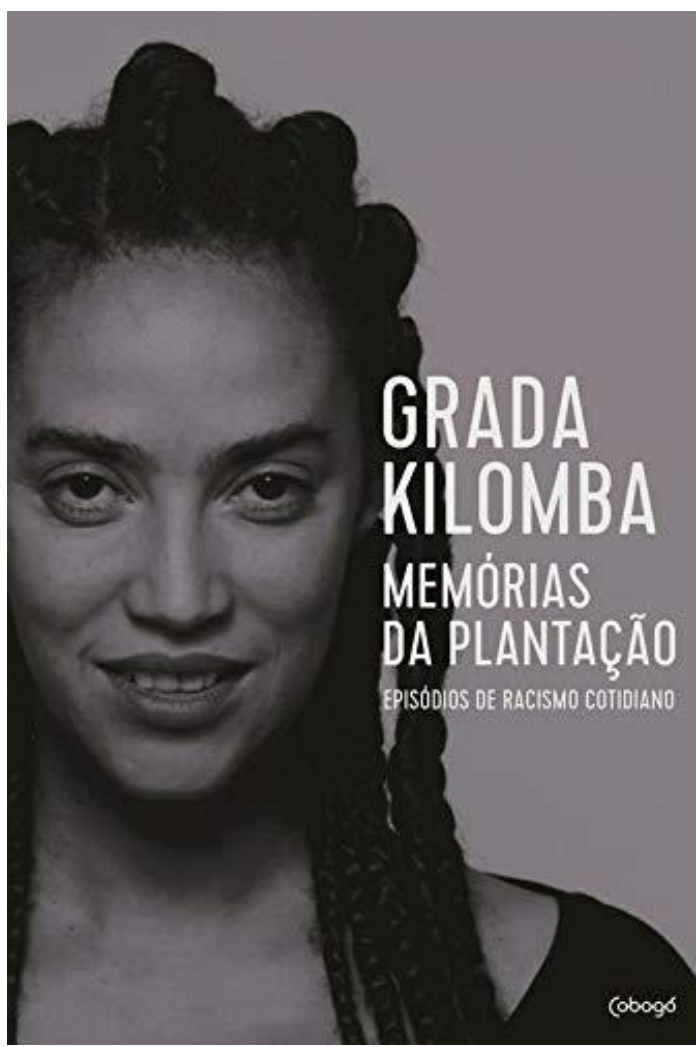

\section{RESUMO}

O presente trabalho trata- se de uma resenha do livro "Memórias de plantação: episódios do racismo cotidiano" de Grada Kilomba. Ao longo do texto, são apresentados elementos do colonialismo e as imbricações sobre o conhecimento e a linguagem, campos de disputa da ação colonial. O trabalho também apresenta considerações sobre a importância da luta antirracista cotidiana.

Palavras-chave: Colonialismo. Racismo. Feminismo.

\section{ABSTRACT}

The present work is a review of the book "Plantation memories: episodes of daily racism" by Grada Kilomba. Throughout the text, elements of colonialism and the overlapping of knowledge and language, fields of dispute for colonial action, are presented. The work also presents considerations about the importance of the daily anti-racist struggle.

Keywords: Colonialism. Racism. Feminism.

Data de submissão: 09 mar. 2020.

Data de aprovação: 02 jun. 2020.

\footnotetext{
${ }^{1}$ Secretaria de Estado da Educação, da Cultura, do Esporte e do Lazer (SEEC/RN). Orcid ID: https://orcid.org/0000-0002-3923-757X. Lattes ID: http://lattes.cnpq.br/6378871154772019. E-mail: patyloreraposo@hotmail.com.

${ }^{2}$ Universidade de Brasília (UNB). Orcid ID: https://orcid.org/0000-0003-2291-0411. Lattes ID: http://lattes.cnpq.br/9867155332294471. E-mail: macianafreitas@hotmail.com.
} 


\section{INTRODUÇÃO}

"Memórias da plantação: episódios do racismo cotidiano", de Grada Kilomba, publicado pela Editora Cobogó em 2019 no Brasil, trata-se de um livro necessário para compreender o racismo cotidiano vivenciado por mulheres negras, ao mesmo tempo promove reflexões sobre colonialismo, gênero, bem como o conhecimento e a linguagem enquanto um campo de disputas sociais.

Kilomba, nascida em Lisboa, artista interdisciplinar, psicóloga, escritora e teórica, com raízes em Angola e São Tomé e Príncipe, traz nessa obra o compartilhamento de experiências e entrevistas, expondo como o racismo se inscreve na dinâmica social, por isso afirma no prefácio a importância de ações que possam fortalecer a luta antirracista. "Parece-me que não há nada mais urgente do que começarmos a criar uma nova linguagem. Um vocabulário no qual nós possamos todas/xs/os encontrar, na condição humana" (KILOMBA, 2019, p. 21).

\section{A OBRA}

"Memórias da plantação", é resultado da pesquisa de doutorado de Grada Kilomba, apresenta uma postura política e biográfica, parte da necessidade de SER, de existir e tornarse sujeito à medida que narra a si mesma. Logo na introdução, a autora nos lembra da função política da língua, pois essa cria, fixa e perpetua relações de poder. Por isso, há um cuidado em explicar algumas terminologias que podem sofrer alteração de sentido quando traduzidas e assim, deslocado o sentido da palavra, desloca-se o sujeito, pois "cada palavra que usamos define o lugar de uma identidade" (KILOMBA, 2019, p. 14).

Kilomba, sob a forma de histórias psicanalíticas, expõe os impactos do colonialismo como elemento fundante das desigualdades e violências diversas praticadas contra a população negra. Ademais, ressalta, ao longo dos capítulos, a invisibilidade da população negra na narrativa histórica oficial, especialmente a mulher negra, indicando a necessidade de epistemologias que apontem para novas perspectivas teóricas. Há um convite à 
desconstrução teórica centrada no ocidentalismo como único produtor de saberes validados, por isso denuncia e apresenta a necessidade de escutar novos sujeitos.

Por isso, Kilomba enaltece que é urgente descolonizar o pensamento, em face disso realiza uma reflexão teórica com base em autores como Frantz Fanon, Bell Hooks e Philomena Essed, nos quais analisa a história colonial e o legado de injustiças sociais que dele decorrem. A sua pesquisa, sob um aporte fenomenológico, analisa as narrativas autobiográficas de mulheres negras moradoras de Berlim, questionando o silêncio impositivo e o racismo vivido nos dias atuais. Nesse contexto, a pesquisadora reconhece elementos que contribuem para esse processo como o discurso acadêmico que legitima a sociedade capitalista e o modelo epistemológico eurocêntrico. A universidade de onde deveria sempre emanar a equidade, vira palco de racismo estrutural.

Para ilustrar essa relação, a autora traz o mito da objetividade e neutralidade, que mantém as posições de autoridade no centro acadêmico, enquanto empurra para a margem as vozes subalternas, sob o argumento do excesso da subjetividade. Para que ocorra a descolonização do conhecimento, um dos caminhos apontados por Grada Kilomba, seria transformar a margem em espaço de criatividade e resistência. Como assinalado pela autora, é importante repensar o mundo moderno/colonial no qual estamos inseridos, assim como observar o sistema social com um olhar crítico, com vistas a criação de perspectivas que possam romper com o racismo institucional.

Outra questão importante na obra é a necessidade de analisar as opressões que se sobrepõem as mulheres negras cruzando categorias como gênero, raça e classe por meio do feminismo interseccional e decolonial, apesar dessas categorias não estarem citadas explicitamente, seus conceitos fundamentam a obra. Dando continuidade ao debate, Kilomba enfatiza inúmeros exemplos para ilustrar as opressões sobre as mulheres negras, defende que a primeira opressão é de raça, e por isso, não se pode falar de gênero sem falar de raça quando se quer combater racismo. Nessa perspectiva, as mulheres negras possuem maiores dificuldades para ter acesso aos direitos fundamentais e políticas afirmadoras de cidadania.

Dentre os capítulos que nos despertaram maior atenção, está "Pode a subalterna falar?" que faz referência ao livro de Spivak no qual, por meio da teoria decolonial, analisa o silenciamento das mulheres negras no campo epistêmico e sua interface com o pensamento 
acadêmico eurocêntrico. Desse ponto de vista, faz-se necessário um ensino pautado numa perspectiva decolonial, crítica e feminista. De acordo com a autora "[...] a academia não é um espaço neutro nem tampouco simplesmente um espaço de conhecimento e sabedoria, de ciência e erudição, é também um espaço de violência" (KILOMBA, 2019, p. 51).

Ao longo dos capítulos, Kilomba fala sobre a necessidade do sujeito negro se libertar dos aprisionamentos da ordem colonial, visto que esta lógica perpassa todos os âmbitos da vida social. Conhecer as formas como o racismo se estrutura na sociedade é essencial para construir ações práticas emancipatórias. O livro, apesar da densidade, deve ser descortinado por todos (as) aqueles que se incomodam com a diferença produzida pela discriminação de pessoas. Kilomba argumenta que é preciso dar voz a todos os sujeitos, dar o direito de falar, de narrar, de ser autor da própria história.

\section{CONSIDERAÇÕES FINAIS}

Portanto, "Memórias da plantação" é um livro interdisciplinar essencial para compreendemos o racismo a partir de uma visão crítica e descolonial, com vistas a criação de práticas que possam contribuir para a luta antirracista. Assim, é uma referência necessária ao articular a dimensão política com a psicanálise para pensar experiências tantas vezes invisibilizadas. No momento como o atual, é central defendermos espaços mais justos e o processo de resistência vivido por feministas negras, intelectuais/ativistas antirracistas.

\section{REFERÊNCIA}

KILOMBA, Grada. Memórias da plantação: episódios de racismo cotidiano. Rio de Janeiro: Cobogá, 2019. 